\section{Cellular Mechanisms of Inflammation Liège, Belgium, 10 February 1995:}

Abstracts

\section{Introduction}

The growing amount of interest in the underlying mechanisms of inflammation prompted us to promote fundamental and applied research in this area. Therefore, to facilitate exchange of knowledge and encourage collaboration between researchers working on various aspects of inflammatory processes, a new contact group was formed under the patronage of the Fonds National de la Recherche Scientifique (FNRS, Belgium) and entitled Cellular Mechanisms of Inflammation.

The first meeting of this contact group held in Liège on 10 February 1995 began with the master lecture by Prof. Vargaftig on the role played by interleukin-5 and eosinophils in allergic pulmonary inflammation. This set the stage for communications by Godding et al. and Kayembe et al. dealing with the effects of cigarette smoke on eosinophil function in vitro and the presence of this inflammatory cell in the sputum from asthmatic subjects, respectively. Results from research on various aspects of cytokine biology including cartilage degradation (Henrotin et al.), cancer (De Groote et al.), cell redox potential of human cultured fibroblasts (Renard et al.), modulation of gelatinase A activation in a fibrosarcoma cell line (Baramova et al.) and human muscular exercise (Bury and Pirnay, Camus et al.) were presented. Courtois et al. described the reduction of hypohalides by a NADH-dependent oxidoreductase activity in Streptococcus sanguis. A prospective study by Venne- man et al. in 300 patients emphasized the role played by the inflammatory response to cardiopulmonary bypass in pancreatic damage following cardiac surgery. In the field of pharmacology, Nagy et al. described a luminol enhanced chemiluminescence method to assess the effects of anti-inflammatory agents on the respiratory burst on human neutrophils and Mathy-Hartert et al. documented the protective effect of ceftazidime on human endothelial cells submitted to $\mathrm{MPO} / \mathrm{H}_{2} \mathrm{O}_{2}$ oxidative stress in vitro. Other aspects of experimental research on inflammatory processes were illustrated by Cantinieaux et al. who showed that secondary iron overload predisposes to infection by impairing neutrophil functions, and Martens et al. who studied the immunomodulatory properties of certain oxytocin antagonists.

The quality of information exchange during this meeting and the diversity of the work presented sum up an amount of knowledge that we are happy to present in the current issue of Mediators of Inflam mation.

This meeting has benefited from the assistance of the Fonds National de la Recherche Scientifique (FNRS, Belgium). We are deeply grateful to all the contributors.

\section{Gérard Camus}

Institut de Chimie, B6, Sart Tilman, 4000 Liège, Belgium 


\section{Effect of cigarette smoke on eosinophil function in vitro}

V. Godding, ${ }^{1,2} Y$. Sibille, ${ }^{1,2}$ P. Staquet, ${ }^{1}$ B. Chatelain, ${ }^{1}$ L. Galanti, ${ }^{1,2}$ and J. P. Vaerman ${ }^{2}$

${ }^{1}$ Cliniques UCL de Mont-Godinne, Yvoir and ${ }^{2}$ Experimental Medicine, Institute of Cellular and Molecular Pathology, UCL, Brussels, Belgium

Increased eosinophil counts have been described in active and passive smokers. Eosinophil inflammation has been found in the bronchial mucosa of smokers with chronic bronchitis. In an animal model, repeated exposure to cigarette smoke increased bronchial hyperreactivity together with increased eosinophils and macrophages in the BAL. We therefore investigated the effect of cigarette smoke extract (CSE) in vitro on eosinophil function.

In three experiments we studied eosinophil (EOS) survival in the presence of CSE at $1 \%$ and $0.1 \%$ concentrations, corresponding to $10^{-6}$ and $10^{-7} \mathrm{M}$ nicotine $/ \mathrm{ml}$. Spontaneous survival at $72 \mathrm{~h}$ was $60 \pm 23.3 \%$. EOS survival was increased by IL- 5 $0.1 \mathrm{ng} / \mathrm{ml}(72.2 \pm 10.3 \%)$ and by GM-CSF $1 \mathrm{pM} /$ $\mathrm{ml}(71.5 \pm 6 \%)$. CSE (1\%) did not influence EOS survival at 24 or $48 \mathrm{~h}$. At $72 \mathrm{~h}$, EOS survival was significantly decreased by CSE (1\%) $(27.0 \pm 20.3 \%$, $p<0.01)$. However, both IL-5 $(61.1 \pm 13 \%)$ and GM-CSF $(75 \pm 4.8 \%)$ significantly suppressed the toxic effect of CSE $(1 \%)(p<0.03)$. CSE $(0.1 \%)$ did not decrease EOS survival at $72 \mathrm{~h}$. We investigated EOS adhesion to respiratory epithelial cells (REC). REC (A549 immortalized cell line) were grown to confluence in 96-well cell culture plates, and then treated for $24 \mathrm{~h}$ with CSE (0.1) (nicotine $\left.10^{-5} \mathrm{M}\right)$, TNF $\alpha(250 \mathrm{U} / \mathrm{ml})$, or the combination of TNF $\alpha$ and CSE at the same concentrations. The expression of ICAM-1 was measured by whole-cell ELISA. As described previously, TNF $\alpha$ significantly increased the expression of ICAM-1 (0.54 \pm 0.06 , $p<0.0001)$. However, CSE $(0.77 \pm 0.07)$ further increased the TNF $\alpha$-induced expression of ICAM-1 $(p<0.0004)$. EOS adhesion to A549 was investigated under the same conditions, and measured using an eosinophil peroxidase (EPO) based assay. In four experiments, EOS adhesion to TNF $\alpha$ treated A549 was increased by CSE $(13 \pm 5.2$ vs. $14.9 \pm 4.8 \%, \quad p<0.01$. In two experiments, the increased EOS adhesion induced by TNF $\alpha$ and CSE was inhibited by anti-CD18 $(7.1 \pm 2.7$ vs. $13 \pm 5.2 \%$ and $8.03 \pm 2.9$ vs. $14.9 \pm 4.8 \%)$ suggesting the Mac1-ICAM-1 interaction takes part in this process. We conclude that in these experiments the toxic effect of CSE (1\%) on EOS survival is suppressed by IL-5 and GM-CSF. CSE enhances the expression of ICAM-1 induced by TNF $\alpha$, and increases eosinophil adhesion to TNF $\alpha$ treated cells. These findings are possibly relevant to the role of eosinophil inflammation in passive and active smokers.

\section{Sputum eosinophilia and bronchial hyperresponsiveness (BHR) in asthma}

J. M. Kayembe, T. Bury, T. Weber, R. Louis and M. F. Radermecker

Department of Pneumology, CHU Sart Tilman, Liege, 4000, Belgium

We compared induced sputum cytology in stable asthmatics (ten allergic and eight non-allergic) and in eleven normal subjects. Sputum was obtained after inhalation of hypertonic saline solution (5\%). Cell counts and differentials were determined. Each subject underwent pulmonary function tests and methacholine responsiveness was measured using the method of Cockroft. We found that sputum induction with $\mathrm{NaCl}(5 \%)$ is a non-invasive alternative for collecting bronchial lining fluid in asthmatic subjects. As previously described by others, we found a higher percentage of eosinophils in sputum from asthmatics than from normal subjects $(25 \pm 3.2 \%$ vs. $1.6 \pm 0.4 \%, p<0.05)$. The inflammatory response (\% eosinophils and neutrophils) tends to be stronger in non-allergic than in allergic asthmatics. The percentage of eosinophils was inversely correlated to the degree of airway obstruction (VEMS/CV) $(r=-0.63, p<0.05)$. No correlation was found between sputum eosinophilia and BHR. These observations suggest a more severe bronchial inflammation in non-allergic asthma and support the view that other factors unrelated to the number of sputum eosinophils may contribute to the onset and maintenance of bronchial hyperresponsiveness.

\section{Cytokines and cartilage degradation}

Y. Henrotin, D. De Groote, A. Labasse, C. Deby, V. Geenen and J. Y. Reginster

Cartilage Metabolism Unit, Department of Radioimmunology, University Hospital of Liège, Sart-Tilman, CHU B23, Liège, Belgium

Human articular chondrocytes isolated from their matrix by three successive enzymatic digestions were cultured for 24 to $72 \mathrm{~h}$, under constant agitation in DMEM supplemented with $1 \%$ Ultroser $\mathrm{G}$.

Recombinant IL-1 $\beta(1,10,50 \mathrm{ng} / \mathrm{ml}), \operatorname{TNF} \alpha(2,20$ $100 \mathrm{ng} / \mathrm{ml}), \mathrm{IL}-6(2,20,200 \mathrm{ng} / \mathrm{ml}), \mathrm{IL}-8$ (0.8, 8, $80 \mathrm{ng}$ ) $\mathrm{ml})$ and $\operatorname{LIF}(1,10,50 \mathrm{ng} / \mathrm{ml})$ were investigated for their actions on proteoglycan (PG), prostaglandin E2 $\left(\mathrm{PGE}_{2}\right)$ and cytokine production. At each concentration used in this study, IL-1 $\beta$ decreased PG production and increased PGE 2 , IL-6, IL- 8 and LIF. TNF $\alpha$ had similar effects to IL-1 $\beta$ on cytokine and PG production. In these culture conditions, $\mathrm{TNF} \alpha$ has no effect on $\mathrm{PGE}_{2}$ production. Interestingly, IL- 6 decreased IL- 8 production by chondrocytes. IL- 8 is an important chemoattractant agent for neutrophils and T-lymphocytes. In this way, IL-6 could limit chondroresorption. IL- 8 induced a moderate increase of IL- 6 production and had no effect on LIF production. On the other 
hand, IL-6 and IL-8 did not modify PG and PGE 2 production. Finally, we observed a stimulation of IL$1 \beta$ production by LIF $(20 \mathrm{ng} / \mathrm{ml})$. LIF also increased IL-6 and IL-8 production and partially inhibited PG synthesis. Meanwhile, using polyclonal antibodies neutralizing IL-1 $\beta$ and $\alpha$ activities, we demonstrated that IL- 1 mediates LIF effects.

In conclusion, IL-1 $\beta$ and TNF $\alpha$ are potent mediators of cartilage degradation, not only by their deleterious effects on matrix synthesis but also by the over-production of IL-6, IL- 8 and LIF. These cytokines may act by autocrine, paracrine and systemic regulation on the development of arthropathies.

\section{Ex vivo cytokine production by whole blood cells from cancer patients}

D. De Groote, ${ }^{1,2} \quad Y$. Gevaert, ${ }^{1,2}$ M. Lopez, $^{1,2} R$ Gathy, ${ }^{1,2}$ F. Marchal, ${ }^{3}$ B. Detroz, ${ }^{3}$ N. Jacquet ${ }^{3}$ and $V$. Geenen $^{1}$

${ }^{1}$ Radioimmunology Laboratory and ${ }^{3}$ Department of Surgery, University of Liège, 4000 Liège, Belgium and ${ }^{2}$ Medgenix Diagnostics Research, 6220 Fleurus, Belgium

It has been hypothesized that the development of cancer could partially result from a diminution of immunocompetence. Using ex vivo cytokine production by whole blood (WB) cells after polyclonal activation, we compared cytokine production levels of cancer patients with those of healthy controls. Seventeen patients without any prior treatment and attending the hospital for oncological surgery (for cancers of several origins) were enrolled in the study. WB was collected in heparinized tubes, diluted $1 / 10$ in RPMI 1640 and incubated for $2,4,24,48$ and $72 \mathrm{~h}$ at $37^{\circ} \mathrm{C}$ in the presence of $5 \mu \mathrm{g} / \mathrm{ml}$ PHA and $25 \mu \mathrm{g} / \mathrm{ml} \mathrm{LPS}$. Cytokine levels in the supernatant were measured by specific immunoassay kits. IL-10 levels after $24 \mathrm{~h}$ of culture, IFN- $\gamma$ and GM-CSF levels after 24 and $72 \mathrm{~h}$ of culture, and LIF levels after $72 \mathrm{~h}$ of culture were significantly lower in cancer patients compared to healthy controls. No significant difference was observed for IL-1 $\beta$, IL-2, IL- 4 , IL- 6 , IL- 8 and TNF $\alpha$ production at any culture time. Our results suggest that the putative immunosuppression of cancer patients might be reflected by their reduced production of immunostimulated cytokines.

\section{Modulation of human cultured fibroblasts cell redox potential: effects on the transcriptional factor NFkappaB activated by IL-1}

\section{P. Renard, M-D. Zachary, C. Bougelet, J. Remacle and M. Raes}

Biochimie Cellulaire, Facultés Notre-Dame de la Paix, 61 rue de Bruxelles, 5000 Namur, Belgium
Reactive oxygen intermediates (ROI) have been shown to be involved in the activation of NFkappaB, a potent and pleitropic transcription factor, activated among others by interleukin-1 (IL-1). As it has been mainly studied in immune system-derived cells, we wanted to investigate the activation mechanisms of NFkappaB when stimulated by IL-1 in human fibroblasts.

NFkappaB is indeed activated by IL-1 in these cells, and we then tested whether any modulation of the cells' main antioxidant enzymes would affect the NFkappaB activation and cell response induced by IL-1. In the first approach, the effects of different specific inhibitors (that is, mercaptosuccinate for glutathione peroxidase, aminotriazole for catalase, and bischlorethylnitrosourea for glutathione reductase) were tested on the activation of NFkappaB induced by IL-1. In the second approach, a transfected cell line of SV40 transformed fibroblasts over-expressing glutathione peroxidase was used and the behaviour of these cells regarding IL-1-induced NFkappaB activation was compared to the corresponding non-transfected cells.

\section{Cytokine modulation of gelatinase $A$ activation in the fibrosarcoma HT1080 cell line}

\section{E. N. Baramova, A. Remacle and J. M. Foidart}

Laboratory of Cell Biology, University of Liege, Tower of Pathology (B23), Sart Tilman, B-4000 Liege, Belgium

Gelatinase A (Mr 72000 type IV collagenase) is a member of the matrix metalloproteinase family, which is synthesized and secreted as a latent proenzyme. The removal of an 80 amino acid $N$-terminal domain yields a Mr 62000 active enzyme capable of participating in extracellular matrix remodelling, which occurs in normal and pathological processes. The activation of gelatinase $\mathrm{A}$ in vitro is induced by treatment with the organomercurial compound $p$ APMA. Little is known about the physiological mechanism of the activation process and its regulation. In contrast to the other matrix metalloproteinases, gelatinase A activation does not involve proteolytic cleavage by stromelysin or serin proteases. It requires prior binding of the proenzyme to the cell plasma membrane where it is processed to its lower molecular mass activated form. In the present study, we investigated the influence of the cytokines epidermal growth factor (EGF), tumour necrosis factor (TNF $\alpha)$ and interferon (INF- $\gamma$ ) on the secretion of gelatinase A by the invasive HT1080 fibrosarcoma cell line and on the cell membranes activation capacities. The obtained results indicate that EGF, TNF $\alpha$ and INF- $\gamma$ induce secretion of activated gelatinase A by the HT1080 cell line. The three cytokines show differential effects on the membrane activation of gelatinase $\mathrm{A}$. 


\section{Activation of leucocytes after prolonged physical exercise}

\author{
T. Bury and F. Pirnay \\ Department of Pneumology, CHU Sart Tilman, Liege, \\ 4000, Belgium
}

This study was designed to compare the effects of three prolonged exercises, varying in their intensity and duration, on leucocytosis, myeloperoxidase (MPO) secretion and cytokine secretion (IL-1 and IL2). Seven healthy subjects underwent three effort trials $\left(45 \% \mathrm{VO}_{2} \max\right.$ for $4 \mathrm{~h} ; 60 \% \mathrm{VO}_{2} \max$ for $3 \mathrm{~h}$; $75 \% \mathrm{VO}_{2} \max$ for $2 \mathrm{~h}$ ) at 1-month intervals. Blood samples were drawn before exercise, at different times during exercise and also after exercise. MPO, IL 1 and IL-2 were measured by radioimmunoassay. Prolonged exercises induced a transient increase in leucocyte count which occurred at all intensity levels. A significant increase in MPO $(+85 \%)$ secretion also occurred after prolonged exercise, whatever the duration or the intensity of exercise, and was independent of the neutrophil mobilization. We have also observed an increase in plasma IL-2 level $(+150 \%)$ and a decrease in plasma IL-2 level (-35\%) after the three prolonged exercises. No correlation was observed between blood mononuclear count and cytokine determination. These observations are in line with the inflammatory response described after prolonged exercises

\section{Mild endotoxaemia and inflammatory response induced by a marathon race}

G. Camus, ${ }^{1}$ J. R. Poortmans, ${ }^{2}$ M. Nys, ${ }^{1}$ G. Deby Dupont, ${ }^{1}$ J. Duchateau, ${ }^{1}$ C. Deby ${ }^{1}$ and M. Lamy ${ }^{1}$ ${ }^{1}$ Centre de Biochimie de l'Oxygène, Université de Liège, Institut de Chimie, B6, Sart Tilman, 4000 Liège; ${ }^{2}$ Chimie Physiologique, Université Libre de Bruxelles, ISEPK, 28, av. P. Héger, 1050 Bruxelles

To address the question of whether endotoxaemia could be involved in the inflammatory response induced by long-term strenuous exercise, 18 male marathon runners [mean age: $41 \pm 2$ (S.E.M.) years] were studied. Their performances in the marathon ranged from $2 \mathrm{~h} 46 \mathrm{~min}$ to $4 \mathrm{~h} 42 \mathrm{~min}$. Four venous blood samples were drawn: at rest, just before the race (baseline); within $15 \mathrm{~min}$ following completion of the marathon; after $1 \mathrm{~h}$ recovery; and the morning after the race. The following humoral markers of the inflammatory response to exercise were measured: polymorphonuclear myeloperoxidase (MPO), anaphylatoxin $\mathrm{C} 5 \mathrm{a}$ (C5a), tumour necrosis factor (TNF $\alpha$ ) and interleukin-6 (IL-6). All these variables were significantly increased $(p<0.001)$ after the race, reaching peak values in most cases in the first blood sample drawn following the completion of the marathon [MPO: $298 \pm 19 \mathrm{ng} / \mathrm{ml}$ (S.E.M.) C5a: $\quad 1.45 \pm 0.32 \mathrm{ng} / \mathrm{ml} ; \quad$ TNF $\alpha: \quad 20 \pm 3 \mathrm{pg} / \mathrm{ml} ; \quad$ IL-6: $88 \pm 13 \mathrm{pg} / \mathrm{ml}$ when compared to baseline (MPO $146 \pm 16 \mathrm{ng} / \mathrm{ml} ; \mathrm{C} 5 \mathrm{a}: 0.27 \pm 0.2 ; \mathrm{TNF} \alpha: 12 \pm 1.5 \mathrm{pg} / \mathrm{ml}$
IL-6: $1.0 \pm 0.5 \mathrm{pg} / \mathrm{ml}$ ). Plasma endotoxin concentration was measured by a chromogenic substrate modification of the Limulus amoebocyte lysate assay (detection limit: $>4 \mathrm{pg} / \mathrm{ml}$ ). An ELISA method was used to determine the serum activity of $\operatorname{IgG}$ antibodies directed toward lipid A and lipopolysaccharides (LPS) from various bacterial smooth and rough strains. Plasma endotoxin values (ranging from 5 to $13 \mathrm{pg} / \mathrm{ml}$, with an exceptionally high value of $72 \mathrm{pg} / \mathrm{ml}$ measured in one runner) were detected in seven subjects within the first hour recovery. Statistical analysis revealed a transient and significant decrease in antiendotoxin IgG activity $(p<0.05)$ in the first blood sample drawn after the race [IgG against a pool of rough LPS $(n=8)$; IgG anti-lipid A $(n=5)$; IgG anti$E$. coli $\mathrm{Ra}(n=8)$; IgG anti- $E$. coli 0127B8 $(n=4)$ ]. There was no correlation between the magnitude of the inflammatory response to exercise, as assessed by the increase in blood level of humoral markers of inflammation, and the changes in plasma endotoxin or anti-LPS IgG activity following the race. From these results, we conclude that the mild, transient endotoxaemia detected in some of our subjects does not play a major role in the observed inflammatory response to a marathon competition.

\section{Reduction of hypohalides by a NADH- dependent oxidoreductase activity in Streptococcus sanguis}

Pb. Courtois, A. Vanden Abbeele and M. Pourtois Laboratory of Stomatology, Free University of Brussels, Faculty of Medicine CP622, route de Lennik 808, B-1070 Brussels, Belgium

Streptococcus sanguis, a colonizer of dental surfaces, resists the hypothiocyanite $\left(\mathrm{OSCN}^{-}\right)$produced by peroxidases in the oral environment. This resistance was attributed to the presence of $\mathrm{NADH}-\mathrm{OSCN}^{-}$ oxidoreductase (NHOR) activity which reduced $\mathrm{OSCN}^{-}$(Carlsson et al., 1983). The aim of this study was to test the sensitivity of $S$. sanguis to hypoiodite $\left(\mathrm{OI}^{-}\right)$produced by peroxidase activities when iodide $\left(\mathrm{I}^{-}\right)$is substituted for thiocyanate $\left(\mathrm{SCN}^{-}\right)$.

Type strain: S. sanguis NCTC 7863 (ATCC 10556). Culture medium: Columbia medium with $5 \%$ defibrinated sheep blood. Growth inhibition assays: survival rates were evaluated after a $30 \mathrm{~min}$ incubation at $37^{\circ} \mathrm{C}$ in the presence and in the absence of a peroxi dase system. Peroxidase systems: $\mathrm{OSCN}^{-}$and $\mathrm{OI}^{-}$ were produced by a two-step enzymic systemglucose/glucose-oxidase $/ \mathrm{SCN}^{-}$or $\mathrm{I}^{-} /$lactoperoxidase. The oxidation power was measured by assaying the oxidation of the $-\mathrm{SH}$ groups from cysteine as an indicator. NHOR activity was assayed according to Oram and Reiter (1966) and Carlsson et al. (1983) in a bacterial lysate centrifuged at $100000 \times \boldsymbol{g}$ for $1 \mathrm{~h}$.

The presence of an NHOR activity $(1.92 \pm 0.2 \mathrm{U} / \mathrm{mg}$ of protein) protected the bacterium against $\mathrm{OSCN}^{-}$ (survival rate: $98 \pm 4 \%$ ). However, a similar amount of $\mathrm{OI}^{-}(450 \mu \mathrm{M}$ oxidized cysteine $/ 30 \mathrm{~min})$ completely 
suppressed the bacterial growth (survival rate $0 \pm 0 \%)$. No $\mathrm{NADH}-\mathrm{OI}^{-}-$oxidoreductase activity could be detected in $S$. sanguis.

\section{Inflammatory response and pancreatic damage following cardiac surgery}

I. Venneman, ${ }^{1}$ G. Deby-Dupont, ${ }^{1,2}$ G. Camus, $^{2}$ V. $D^{\prime}$ Ans, ${ }^{1}$ A. Albert, ${ }^{3}$ R. Larbuisson, ${ }^{1}$ G. Hartstein ${ }^{1}$ and M. Lamy

${ }^{1}$ Department of Anesthesiology and Intensive Care Medicine;

${ }^{2}$ Centre for the Biochemistry of Oxygen;

${ }^{3}$ Department of Computer Science, University of Liège, CHU, Sart Tilman, B35, 4000, Liège, Belgium

To assess the extent to which the inflammatory response triggered by cardiopulmonary bypass is involved in pancreatic damage following cardiac surgery, 300 patients undergoing artery bypass grafting or valve replacement were studied. Serum levels of immunoreactive trypsin (IRT), pancreatic isoamylases and lipase were used as biochemical markers of pancreatic damage. Plasma levels of $\mathrm{C}$-reactive protein (CRP); $\alpha_{2}$-macroglobulin $\left(\alpha_{2} \mathrm{M}\right), \alpha_{1}$-proteinase inhibitor $\left(\alpha_{1} \mathrm{PI}\right)$, polymorphonuclear elastase (EL) and myeloperoxidase (MPO) were measured. Nine blood samples were taken as follows: before operation (baseline), immediately after surgery (return to intensive care unit), 8, 15,28 h and 2, 3, 4 and 8 days after surgery. Pancreatic injury was defined as an increase in the serum levels of the three biochemical markers of pancreatic damage above the following values, considered as upper limits of normal: IRT, $70 \mathrm{ng} / \mathrm{ml}$; pancreatic isoamylases, $35 \mathrm{IU} / 1$; lipase, $200 \mathrm{IU} / 1$. Patients in whom these three variables exceeded the upper limits of normal on at least one occasion after CPB were defined as having suffered from pancreatic damage (Group P: presence of cellular pancreatic damage, CPD, $n=92$ ). The other patients (absence of CPD) were included in Group $\mathrm{P}^{-}(n=208)$. Biochemical indices of pancreatic damage showed a similar timecourse in both groups. Two sequential phases of release of these pancreatic enzymes were observed: the first within $24 \mathrm{~h}$ of surgery, while the second, more intense, started on day 4 and reached a peak on day 8 after surgery. These variables were significantly higher in Group $P$ than in those measured in Group $\mathrm{P}^{-}$at each time point, including baseline. While $\alpha_{2} \mathrm{M}$ decreased sharply after surgery and remained significantly lower than baseline $(p<0.001)$ up to day 8 , CRP and $\alpha_{1}$ PI increased as a function of time, reaching peak values significantly different from control $(p<0.001)$ within the first few days following operation. EL $(n=47)$ and MPO $(n=300)$ levels were markedly elevated $(p<0.001)$ at the end of CPB. These variables remained significantly greater $(p<0.001)$ than pre-operative values post-operatively. By multivariate analysis, it was found that the delayed peak in pancreatic enzymes in group $\mathrm{P}$ was closely related to the changes in the humoral inflammatory markers. Pre-operative levels of trypsin and amylase were independent predictors of post-operative CPD. From these results, we conclude that this inflammatory response significantly contributed to the delayed rise in the biochemical indices of CPD following cardiac surgery.

\section{Luminol-enhanced chemiluminescence method for assessing the effect of non- steroidal anti-inflammatory drugs on the respiratory burst of human neutrophils}

A.-M. Nagy, ${ }^{1}$ N. Parij, ${ }^{1}$ M. Lejeune, ${ }^{2}$ B. Cantinieaux, ${ }^{2}$ $P$. Fondú ${ }^{2}$ and J. Nève ${ }^{1}$

${ }^{1}$ Department of Pharmaceutical Organic Chemistry, Institute of Pharmacy, Free University of Brussels, Campus Plaine, 205-5, B-1050 Brussels;

${ }^{2}$ Laboratory of Haematology, Saint-Pierre Hospital, 322, rue Haute, B-1000 Brussels, Belgium

Reactive oxygen species are involved in host defence mechanisms and usually are products of cellular metabolism. Under a variety of stimuli, polymorphonuclear neutrophils $(\mathrm{PMN})$ generate $\mathrm{O}_{2}^{-}, \mathrm{OH}^{*}, \mathrm{H}_{2} \mathrm{O}_{2}$, and $\mathrm{ClO}^{-}$. In some excessive inflammatory responses, free radical production by the PMN may be detrimental to cells and tissues.

In the present study, the antioxidant effect of NSAIDs on the respiratory burst of stimulated PMN was investigated using luminol-enhanced chemiluminescence (L-ECL). CL of crude and purified PMN preparations were compared. Several stimuli, such as opsonized zymosan (OZ), $N$-formyl-methionyl-leucylphenylalanine (fMLP) and phorbol myristate acetate (PMA), were also studied. Luminol and cell concentrations were determined. Finally, knowing that numerous drugs are reported to affect the response of neutrophils, the effect of indomethacin and diclofenac on the L-ECL of activated PMN was examined. A significant dose-dependent inhibition $(p<0.001)$ of the $\mathrm{CL}$ was observed with these drugs. Indomethacin and diclofenac concentrations required for half inhibition $\left(\mathrm{IC}_{50}\right)$ of the L-ECL of OZ activated PMN were $(3.4 \pm 1.0) \times 10^{-5} \mathrm{M}$ and $(3.4 \pm 1.2) \times 10^{-5} \mathrm{M}$, respectively $(n=6)$.

These preliminary results demonstrate that L-ECL is a suitable analytical technique for studying the phagocytic function of human blood neutrophils and their response to antioxidant molecules.

This study was supported by a FIRST project (Ministère de la Région Wallonne, Convention n²657).

\section{Endothelial cell cytotoxicity induced by myeloperoxidase: protection by ceftazidime}

M. Matby-Hartert, G. Deby-Dupont, J. Jadoul, M. Lamy and C. Deby

University of Liège, Centre for the Biochemistry of Oxygen and Department of Anesthesiology and Intensive Care Medicine, 4000 Liège, Belgium; and Glaxo SA 
Among the mechanisms underlying inflammationinduced tissue destruction is the production of toxic oxidant species such as hypochlorous acid (HOCl), a potent cytotoxic compound derived from the neutrophil myeloperoxidase (MPO) catalysed reaction of $\mathrm{H}_{2} \mathrm{O}_{2}$ with $\mathrm{Cl}^{-}$. Oxidant species are particularly deleterious to endothelial cells during the process of polymorphonuclear neutrophil (PMN) adherence to the endothelial layer. The aim of the present study was to assess the protective effect of ceftazidime (CAZ), an antibiotic widely used for the treatment of septic patients, on endothelial cells submitted to $\mathrm{MPO} / \mathrm{H}_{2} \mathrm{O}_{2}$ oxidative stress in vitro. Endothelial cells were isolated from human umbilical veins (human umbilical vein endothelial cells, HUVEC) and loaded with MPO. MPO uptake was demonstrated by measuring intracellular MPO enzymatic activity. The cytotoxicity of $\mathrm{MPO} / \mathrm{H}_{2} \mathrm{O}_{2}$ on HUVEC was assessed by the release of previously incorporated ${ }^{51} \mathrm{Cr}$. An index of cytotoxicity (IC) based on the measurement of the amount of ${ }^{51} \mathrm{Cr}$ released into the culture medium was calculated. Incubation of HUVEC for $2 \mathrm{~h}$ in the simultaneous presence of MPO $(5 \mu \mathrm{g} / \mathrm{ml})$ and $\mathrm{H}_{2} \mathrm{O}_{2}\left(10^{-4} \mathrm{M}\right)$ yielded low IC values $(5.05 \pm 2.1 \%$, mean \pm S.D. $)$. However, when HUVEC were first incubated for $2 \mathrm{~h}$ with MPO to allow uptake of this enzyme, followed by induction of oxidative stress by addition of $\mathrm{H}_{2} \mathrm{O}_{2}$, a significant increase of IC was observed $(39.92 \pm 0.64 \%)$. Under these experimental conditions, dose-dependent protection was obtained when CAZ was added with MPO $(26 \pm 0.9$ $58.8 \pm 3.9 ; 92.4 \pm 1.7 \%$ protection for $\mathrm{CAZ}$ concentrations of $10^{-5}, 4 \times 10^{-5}$ and $10^{-3} \mathrm{M}$, respectively). This protective effect was comparable to that obtained with methionine, a well known $\mathrm{HOCl}$ scavenger. CAZ $\left(10^{-3} \mathrm{M}\right)$ also protected HUVEC incubated for $2 \mathrm{~h}$ with $\mathrm{HOCl} 10^{-3} \mathrm{M}(77.9 \pm 11.5 \%$ protection). In contrast, $\mathrm{CAZ}$ was not protective when cells were submitted to $\mathrm{H}_{2} \mathrm{O}_{2}$ stress. From these results, we conclude that $\mathrm{CAZ}$ neutralized MPO activity by inactivating $\mathrm{HOCl}$.

\section{Iron overload and predisposition to infection}

B. Cantinieaux, A. Janssens, V. Kerrels and P. Fondu Laboratory of Haematology, Saint-Pierre Hospital, 322, rue Haute, B-1000 Brussels, Belgium

A large number of studies have demonstrated the existence of a tight association between secondary iron overload and an increased susceptibility to infections. Altered phagocyte functions of polymorphonuclear neutrophils (PMN) have been reported in patients with secondary haemosiderosis such as in decompensated cirrhosis, thalassaemia major, and polytransfused haemodialysis patients. Phagocytosis was negatively correlated with the serum ferritin level in decompensated cirrhosis and polytransfused haemodialysis patients. Treatment of these patients with desferrioxamine improved the phagocytosis of their PMN. Moreover, the use of recombinant human erythropoietin for 1 year in haemodialysis patients improved the phagocytosis rate.

In vitro incubations of PMN from healthy controls with iron salts or with serum from iron-overloaded patients, induce phagocytosis abnormalities similar to those observed in patients' PMN. The PMN from secondary iron overloaded patients contain an endogenous iron source for the oxidant radical reactions since they contain 4- to 5-fold more iron and ferritin than those of healthy controls. The overproduction of oxygen free radicals can explain the membranous phagocytosis abnormalities. The toxic effect of serum from secondary haemosiderosis patients on PMN phagocytosis can be attributed to ferritin associated iron.

In conclusion, secondary iron overload predisposes to infections at least by impairing PMN functions.

\section{Immunomodulatory properties of cyclic hexapeptides oxytocin antagonists: a new approach to modulating inflammatory processes?}

H. Martens, ${ }^{1}$ D. De Groote, ${ }^{2}$ and V. Geenen ${ }^{1}$

${ }^{1}$ Neuroendocrino-Immunology Unit, Radiolmmunology Laboratory, University of Liege, Belgium;

${ }^{2}$ Medgenix Group, Fleurus, Belgium

Our group is involved in the study of processes by which the neuroendocrine system communicates with the immune system. We have tested new cyclic hexapeptide oxytocin (OT) antagonists that possess a non-peptidic part, giving them a long half-life compared with natural neurohypophysial (NHP) peptide antagonists (Bock et al., J Med Chem 33: 2321).

In a whole-blood culture model (which allows conservation of interactions between cells) (De Groote $e t$ al., Cytokine 4: 239), we have studied the production of cytokines IL-1, IL- 6 , IFN- $\gamma$, TNF $\alpha$ and GM-CSF induced with anti-CD3 and in presence or absence of three OT antagonists. OT antagonists induced an inhibition of IL-1, IL- 6 and IFN- $\gamma$ down to $20 \%$ of basal value after $72 \mathrm{~h}$, whereas no such effects were seen on TNF $\alpha$ and GM-CSF. This was essentially different from the inhibitory effects of cyclosporine A on TNF $\alpha$ and GM-CSF. Although a difference between men and women was shown, probably due to the higher number of OT receptors in women, the mechanism of such inflammatory-related cytokine inhibition remains to be identified. Two hypotheses may be considered: (1) an interaction with T cells that have been demonstrated to bear NHP receptors (Martens et al., Prog Neuroendocrino Immunol 5: 31), or (2) an indirect action on monocyte/macrophage components.

Nevertheless, these experiments open a new way to modulate inflammatory immune processes using specific antagonists of neuroendocrine peptide receptors. 


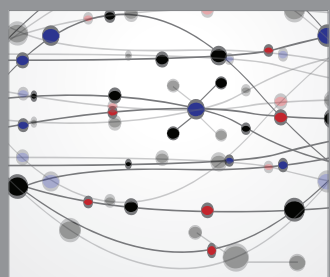

The Scientific World Journal
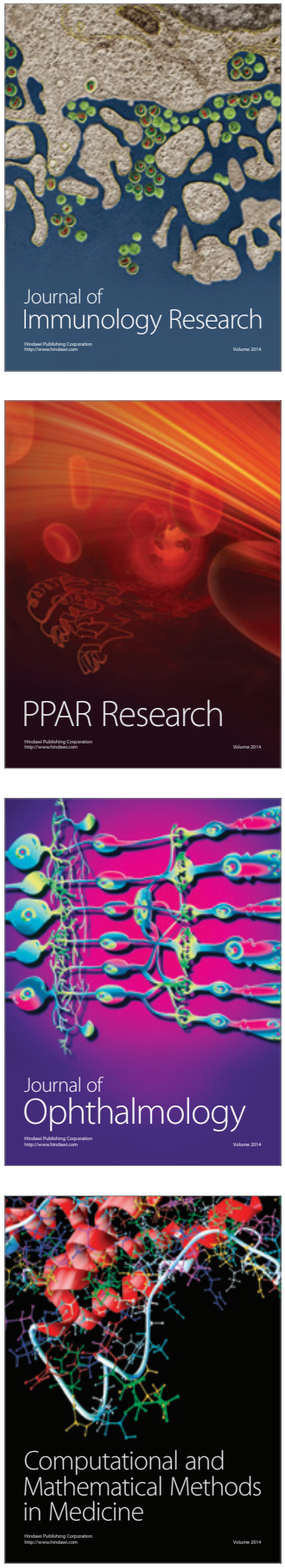

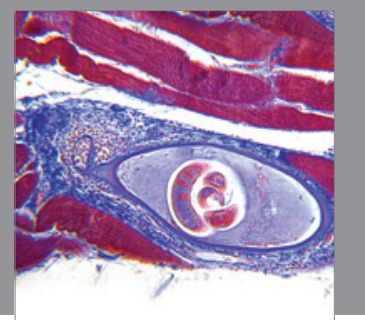

Gastroenterology

Research and Practice
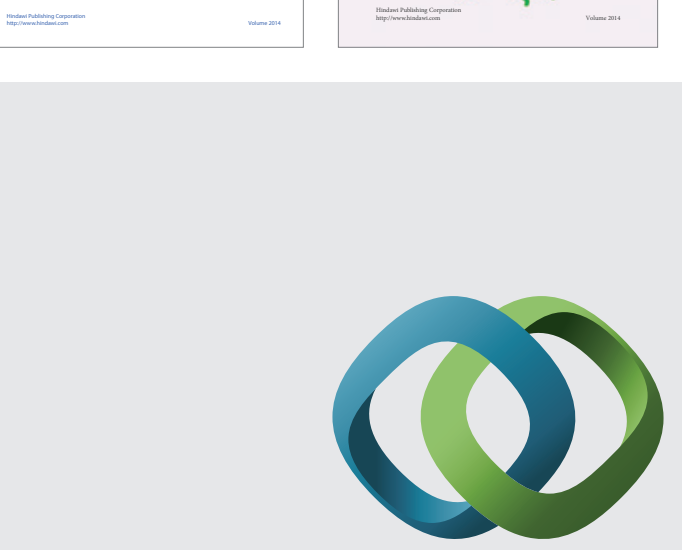

\section{Hindawi}

Submit your manuscripts at

http://www.hindawi.com
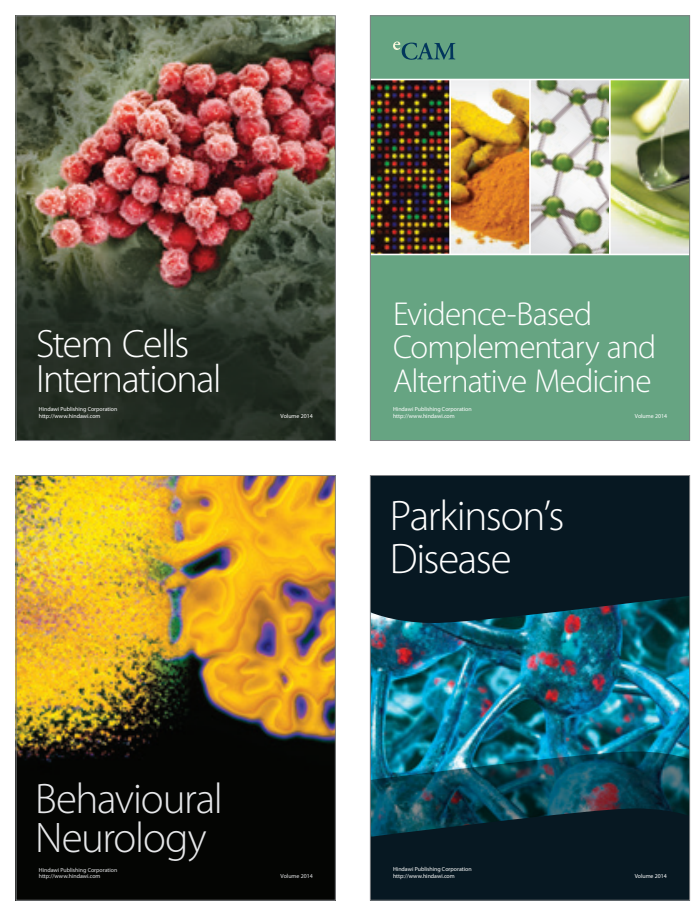

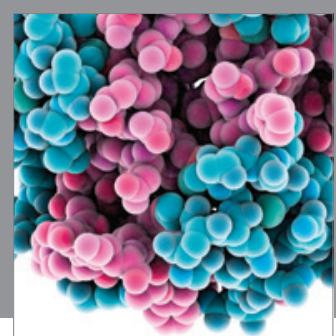

Journal of
Diabetes Research

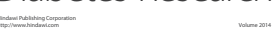

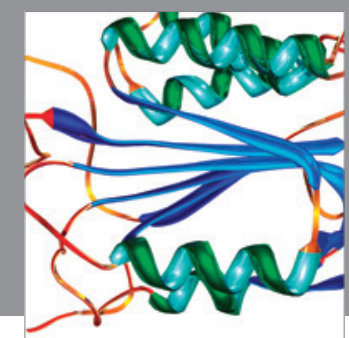

Disease Markers
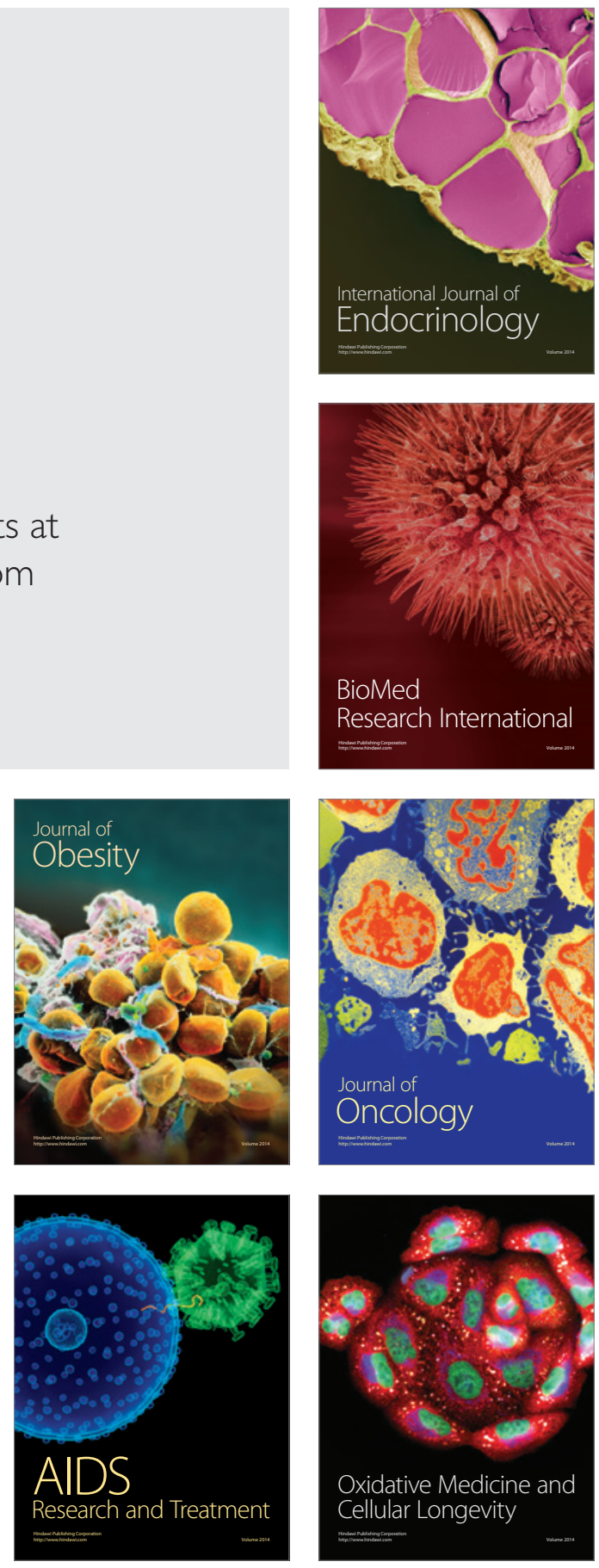